\title{
Mediterranean Built Environment and Weather as Modulator Factors on Physical Activity: Cross-Sectional Study ${ }^{\dagger}$
}

\author{
Antoni Colom ${ }^{1,2, *}$, Maurici Ruiz ${ }^{3}$, Josep Muncunill ${ }^{1}$, Julia Wärnberg ${ }^{4}$, Montserrat Compa 5 , \\ Javier Baron ${ }^{6}$, Napoleón Pérez ${ }^{6}$, Marga Morey ${ }^{1,2}$, Elena Cabeza ${ }^{7}$, Miquel Fiol 1,2 and \\ Dora Romaguera ${ }^{1,2}$
}

1 Instituto de Investigación Sanitaria Illes Balears (IdISBa), University Hospital Son Espases, Palma de Mallorca 07120, Spain; josep.muncunill@ssib.es (J.M.); marga.morey@yahoo.es (M.M.); miguel.fiol@ssib.es (M.F.); mariaadoracion.romaguera@ssib.es (D.R.)

2 CIBER Fisiopatología de la Obesidad y Nutrición (CIBEROBN), Instituto de Salud Carlos III, 28029 Madrid, Spain

3 Servicio de SIG y Teledetección, Vicerectorat d'Innovació i Transferència, Universitat de les Illes Balears, 07120 Palma de Mallorca, Spain; maurici.ruiz@uib.es

4 Departamento de Enfermería, Facultad de Ciencias de la Salud, Universidad de Málaga, Instituto de Investigación en Biomedicina (IBIMA), 29016 Málaga, Spain; jwarnberg@uma.es

5 Instituto Español de Oceanografía, Centro Oceanográfico de Baleares, 07015 Palma, Spain; montserratcompa@gmail.com

6 Departamento de Salud Pública, Facultad de Medicina, Universidad de Málaga, Instituto de Investigación en Biomedicina (IBIMA), 29016 Malaga, Spain; baron@uma.es (J.B.); napoleon.perez@uma.es (N.P.)

7 Servei de promoció de la salut, DG Salut Pública i Participació, Conselleria de Salut, Grup d'investigació en Salut Pública de les Illes Balears (GISPIB) - Instituto de Investigación Sanitaria Illes Balears (IdISBa), 07120 Palma de Mallorca, Spain; cabezaelena@gmail.com

* Correspondence: antonicolom@gmail.com; Tel.: +34-871-20-5050 (ext. 64530)

+ Presented at the 1st International Electronic Conference on Environmental Health Sciences, 15 November-7 December 2018; Available online: https://iecehs-1.sciforum.net/.

Published: 14 November 2018

\begin{abstract}
Background: When promoting physical activity practice, it is important to consider the plausible environmental determinants that may affect this practice. We aimed to explore the impact of objectively measured Public Open Spaces (POS) on objectively measured and self-reported physical activity and the influence of weather on this association, in a Mediterranean sample of senior adults with overweight or obesity and the metabolic syndrome. Method: Cross-sectional analyses based on 218 PREDIMED-Plus trial participants aged 55 to 75 years, from Palma de Mallorca (Spain). Indicators of access to POS were assessed in a $1.0 \mathrm{~km}$ sausage network walkable buffer around each participant's residence address using geographic information systems. Mean daily minutes of self-reported leisure-time brisk walking, and accelerometer objectively measured moderate-to-vigorous physical activity in bouts of at least $10 \mathrm{~min}$ (OM-MVPA) were measured. To investigate the association between access to POS and physical activity, generalized additive models with Gaussian link function were used. Results: Better access to POS was not statistically significantly associated with self-reported leisure-time brisk walking. A positive significant association was only observed between the distance of healthy routes contained or intersected by buffer and OM-MVPA. This association was only evident on non-rainy days. Conclusions: In this elderly population living in a Mediterranean city, only healthy routes contained or intersected by a $1 \mathrm{~km}$ sausage network walkable buffer influenced the accelerometer objectively measured moderate-to-vigorous physical activity in bouts of at least $10 \mathrm{~min}$ and rainy conditions during the accelerometer period appeared to be an important factor related to active ageing.
\end{abstract}


Keywords: physical activity; leisure; walking; built environment; public open space; GIS; weather; elderly; senior adults; PREDIMED-Plus trial

\section{Introduction}

Physical inactivity is a global pandemic: in 2016 more than one in four adults (27.5\% or 1.4 billion people) were physically inactive [1]. Regular physical activity has shown to reduce the risk of cardiovascular disease, hypertension, diabetes, and can help maintain a healthy weight [2].

A wide range of environmental factors has been attributed to facilitating physical activity as a means of transportation and recreation. On the one hand, the urban built environment and public open spaces (POS), such as parks, beaches or sport facilities, are plausible determinants of physical activity practice in older adults, but some controversy across studies exist $[3,4]$. On the other hand, only a few studies, in northern European popultations have explored the impact of weather conditions on physical activity (PA) practice in older adults [5-7], leaving out the Mediterranean countries which have the highest prevalence of physical inactivity in Europe Region [8].

To the best of our knowledge, there are no previous studies on the joint interaction of both factors, POS and weather conditions, and their effect among elderly populations in the Mediterranean basin.

Here we explore the cross-sectional association of access to POS on self-reported and objectively-measured PA and the interaction of weather conditions on this association in older adult participants from the PREDIMED-Plus-Baleares trial.

\section{Materials and Methods}

\subsection{Study Population}

The ongoing PREDIMED-Plus trial, an ongoing 6-year multi-center, randomized, parallel-group designed to evaluate a lifestyle strategy for the primary prevention of cardiovascular mortality in 6874 senior adults (the protocol is available at http://predimedplus.com/ and the trial was registered at the International Standard Randomized Controlled Trial http://www.isrctn.com/ISRCTN89898870). Participants were community-dwelling adults (aged 5575 in men; $60-75$ in women) with BMI $\geq 27$ and $<40 \mathrm{~kg} / \mathrm{m}^{2}$, enrolled from primary care facilities in Spain between 5 September 2013 to 31 October 2016 who met at least 3 or more metabolic syndrome individual components [9]. The lifestyle intervention consists of an energy-restricted traditional Mediterranean diet (MedDiet), physical activity (PA) promotion and behavioural support, in comparison with a usual care intervention only with energy-unrestricted MedDiet (control group). The PREDIMED-Plus study protocol can be found at http://predimedplus.com.

This is a cross-sectional analysis of baseline data extracted 1/15/18 of 335 participants enrolled from primary care facility dependents of the University Hospital Son Espases, one of the 23 recruitment centers participating in the PREDIMED-Plus trial. The study protocol and ethical approval were granted by the Committee of Research Ethics of the Balearic Islands (CEI-IB) review boards, and all participants provided written informed consent.

Participants who reported living outside the city limits of Palma de Mallorca $(n=16)$; those with no accelerometer data (did not wear accelerometer at all; $n=100$ ); and those with less than 4 days of valid accelerometer data $(n=1)$, were excluded from the analyses, leaving a final sample size of 218 participants.

\subsection{Neighborhood Exposure to Public Open Spaces (POS)}

POS were evaluated using the geographic area around each participant's home. The location of each participant's residence, reported at baseline, was geocoded using the web processing service provided by the CartoCiudad, a project run by the National Geographic Institute of Spain, which is freely available for download (www.cartociudad.es). Using the software ArcGIS 10.5.1 (ESRI; 
Redlands, CA, USA), for each participant's residence location, we applied a sausage network buffer methodology. The full methodology has been described elsewhere [10]. Briefly, using only the walking and/or cycling street network and ignoring routes restricted to pedestrians, such as freeways, we obtained the area within $1 \mathrm{~km}$ walkable street distance of an each participant's residence location moving along the street walkable network and a radius of 30 meters either side of the street network [11] (Figure 1). Next, using tabulate intersection tool from ArcGIS 10.5.1 software, three different POS were quantified within or partially within each participant's residence sausage network walkable buffer.

To determine the distance to the closest POS in the absence of POS entry points, we transformed the boundaries of each polygon or line to points spaced every $20 \mathrm{~m}$ from each other, allowing us to eliminate the measurement error caused by the shape and size of the resource [12] (Figure 1). Distances to the closest POS boundary were identified using the origin-destination cost matrix function. The function calculates a walking and cycling street network distance from the participant's residential addresses to a nearest POS boundary.

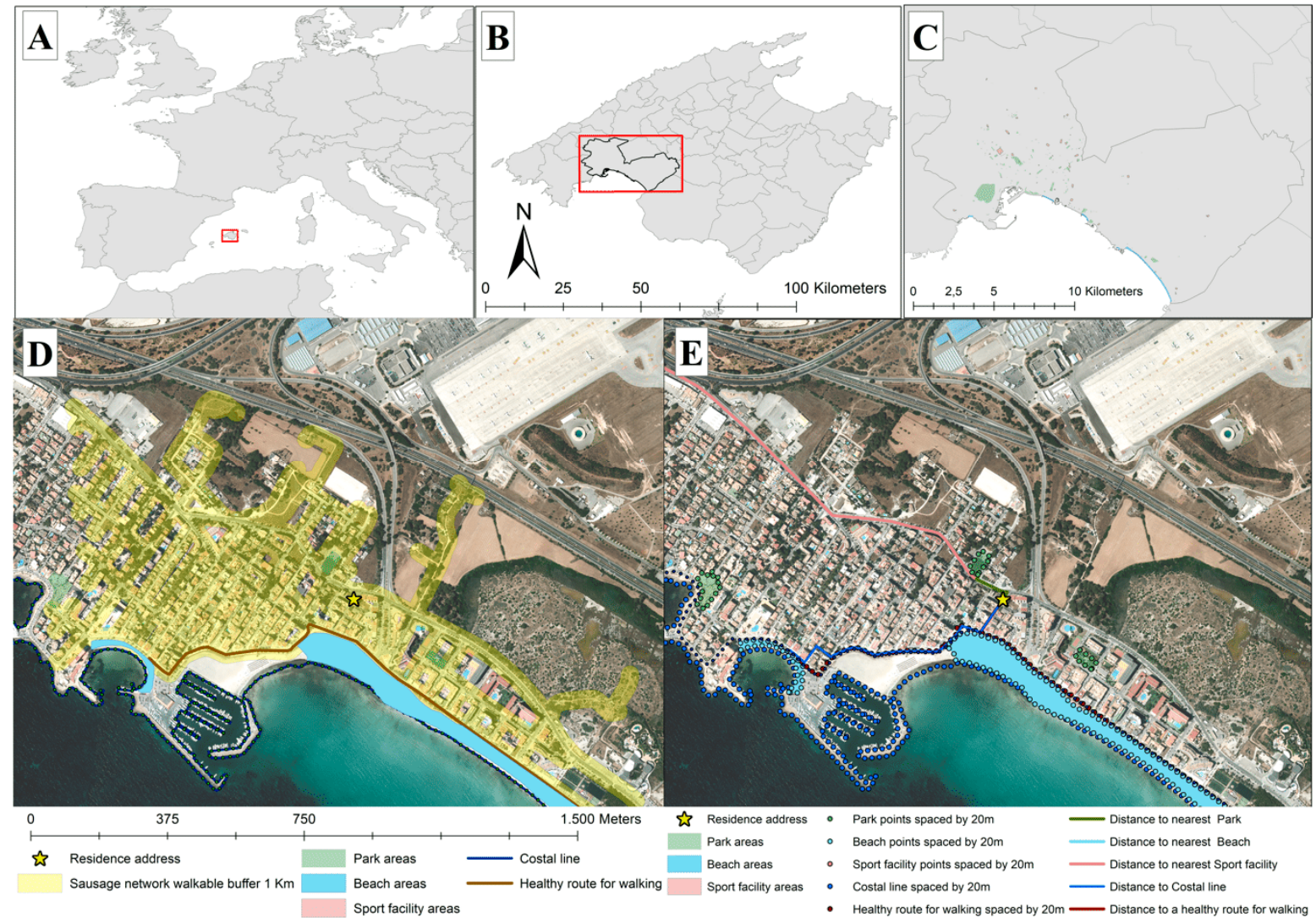

Figure 1. Study area of Palma, Mallorca (A-C). Example of neighborhood exposure to public open spaces (POS) with a $1 \mathrm{~km}$ sausage network walkable street buffer around of the residence address represented by the yellow area (D) and the point boundaries of the Built Environments (E).

Public Open Spaces (POS)-The following POS (proximity, count, and total area) were calculated, all of which are commonly used in physical activity and health research. Data layers were generated during 2014 from three different datasets sources: (1) Sports facilities from the Municipal Sports Institute of the City of Palma. Sports facilities included only public facilities owned and maintained by the city council relevant to our population: multi-sports centers, gyms, covered and non-covered swimming pools, indoors and outdoors courts (basketball, tennis, football), and bocce ball ranks. All privately run sports facilities (golf courses, private gyms or private courts) were excluded from the definition, because their access is neither open nor public; (2) Beaches with permanent life-saving service available from the City Council of Palma; (3) Parks from the Department of Infrastructure and Accessibility of the City Council of Palma. 
We computed the number and area of each POS within or partially within the sausage network walkable buffer separately as well as the sum of the number and area of all types of POS.

For the distance to the nearest of each POS for each participant's residence, we considered sports facilities, beaches, and parks separately. We did not consider distance to any POS as an exposure because, for $85.3 \%$ of the sample, the nearest POS is a park. The distance of the coast within or partially within each participant's buffer and proximity to the coast as a potential resource for the practice of physical activity was included, since the city of Palma is a coastal city [13]. In addition, we considered distance into the buffer and proximity to healthy routes for walking, promoted by the local government health policies, that may directly or indirectly influence active travel [14].

\subsection{Outcome Measure: Physical Activity}

For this analysis, we evaluated both objectively-measured physical activity and self-reported physical activity, assessed at baseline.

Self-reported leisure-time brisk walking-Participants completed the REGICOR Short Physical Activity Questionnaire [15], a validated short version of the validated Spanish Minnesota leisure time PA questionnaire (MLTPAQ) [16,17]. The REGICOR questionnaire collects information on walking, the main mode of physically active transportation [15], and included a specific question to collect information about the leisure-time brisk walking, frequency (number of days) and duration (min/day) performed during a representative month. Time spent in leisure-time brisk walking (accumulated minutes/day) was computed as the sum of the frequency multiplied by the duration of each activity and divided by 30 .

Objectively-measured moderate-to-vigorous physical activity (OM-MVPA) (10 $\mathrm{min}$ bouts) - Participants at the baseline visit were asked to wear a wrist-worn triaxial accelerometer (GENEActiv, ActivInsights Ltd, Kimbolton, United Kingdom), on their non-dominant wrist nonstop for seven consecutive 24-hour days. The accelerometer was sampled at $40 \mathrm{~Hz}$ with a $\pm 8 \mathrm{~g}$ dynamic range, and data were stored in gravity $(g)$ units $\left(1 g=9.81 \mathrm{~m} / \mathrm{second}^{2}\right)$. Accelerometer data were processed and scored using R (R Core Team, Vienna, Austria) and R-package GGIR (version 1.2-5), available on CRAN (https://cran.r-project.org) and managed on servers at the University of Malaga one of the 23 recruitment centers participating in the PREDIMED-Plus trial. For scoring physical activity, a 'valid day' was defined as $\geq 2$ valid hours of wear. Only participants with four or more valid days were included in analyses [18]. These methods were consistent with other authors recommendations [19]. The maximum time was nine consecutive days, both daytime and nighttime. On valid days, the duration of objectively-measured (accumulated minutes/day) was based on the moderate-to-vigorous physical activity (MVPA) which was defined as intensity greater than 100 milligravity and at least 10 minutes in a row. The average in min/day of MVPA was calculated during accelerometer wear time.

Figure 2 shows the correlations between self-reported leisure-time brisk walking and OM-MVPA, assessed at baseline. Of note, self-reported leisure-time brisk walking and OM-MVPA were significantly and strongly correlated with each other (Figure 2) 


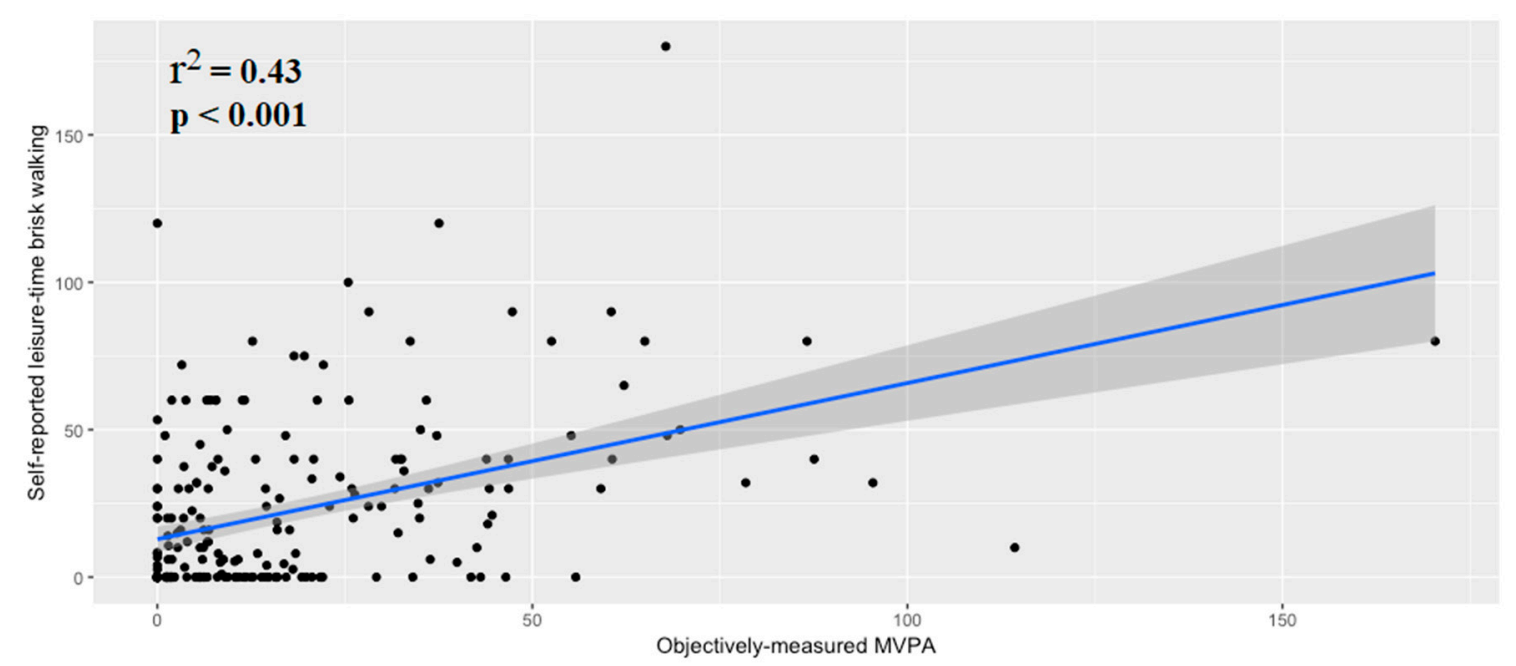

Figure 2. Correlations between self-reported leisure-time brisk walking and OM-MVPA. Abbreviations: $p, p$-value; $\mathrm{r}^{2}$, coefficient of determination; association between variables are evaluated with Pearson test.

\subsection{Covariate Assessment}

Covariables information on gender, education level (primary school or less; secondary school or higher), and self-rated health were collected at the baseline using a self-reported questionnaire. Self-rated health was measured by the question "How would you rate your general health?" from an adapted version of previously published questionnaires of health-related quality of life that were validated for the Spanish population [20]. Participants reporting excellent, very good, and good health were categorized into one group, and those reporting fair and poor were in the other group.

\subsection{Climatological Assessment}

Mean measurements of precipitation $(\mathrm{mm})$ data were collected during accelerometer wearing period and was obtained for each participant from the closest euclidian distance or distance "as crow-flies," from participants' resident weather station (Figure 3). Since a large number of days had no precipitation, days without rain (i.e., $0 \mathrm{~mm}$ ) were categorized into one group (without rain), and those with some rain were in the other group (with rain). 


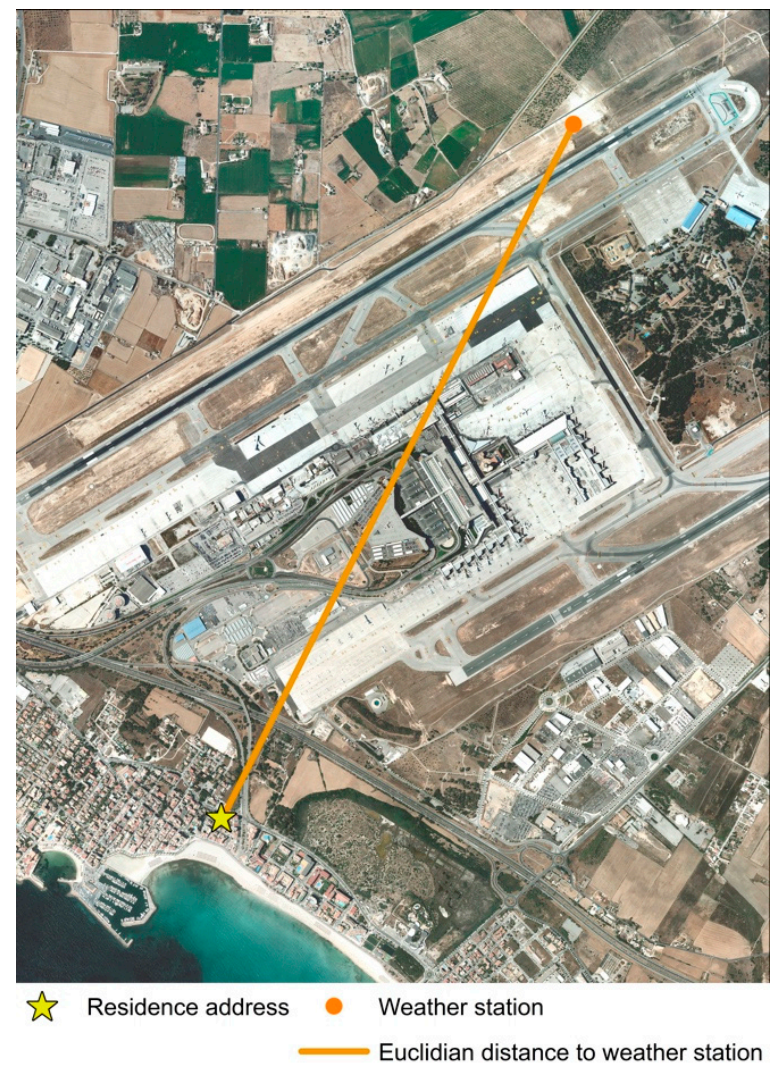

Figure 3. Example of closest euclidian distance from participants' resident weather station.

\subsection{Statistical Analysis}

A descriptive analysis for the outcomes variables (min/day) self-reported leisure-time brisk walking and OM-MVPA, were performed comparing participant demographic characteristics and the precipitation variable. The Compare Groups package for $\mathrm{R}$ [21] was used to determine the significance of the trend.

Associations of objectively measured POS variables with self-reported leisure-time brisk walking and OM-MVPA were estimated using generalized additive models (GAMs) with Gaussian link function, and curvilinearity of relations was assessed with thin-plate spline smooth terms $[22,23]$ adjusted for gender, age, education level, and self-rated health. We examined the interaction of weather conditions, on the association of objectively measured POS variables with OM-MVPA. The significance of interactions was assessed by adding cross-product terms between our exposure of interest and weather (classified in two categories: rainy or not-rainy periods).

All analyses were conducted in R (R Development Core Team, 2011) using packages 'Compare Groups' [21], 'mgcv' [24], 'gamm4' [25].

\section{Results}

\subsection{Descriptive Statistics}

Table 1 shows descriptive characteristics of the 218 participants with at least four valid days of objectively-measured physical activity data. The mean age was 65.2 years with a range from 55 to 75 years. Almost $40 \%$ of participants had secondary school or higher. Around $70 \%$ of participants reported excellent/very good/good health.

Taking into account self-reported leisure-time brisk walking, $61.5 \%$ of the population $(44.8 \%$ men and $55.2 \%$ women) and according to OM-MVPA, $72.0 \%$ of the population $(40.8 \%$ men and $59.2 \%$ women) did not meet the minimum recommended level of WHO physical activity guidelines (i.e., at least $150 \mathrm{~min} /$ week of MVPA) [26] (data not shown in tables). On average, participants accumulated about $8( \pm 1.3)$ valid days of accelerometer and wear time $17.6 \mathrm{~min} /$ day of MVPA (data 
not shown in tables). In our study, poorer self-rated health was associated with a lower level of physical activity (Table 1). Women showed significantly lower OM-MVPA than men. Precipitation was not significantly associated with either self-reported or objectively measured PA in this sample.

Table 1. Study population demographic characteristics according to min/day self-reported leisure-time brisk walking and OM-MVPA.

\begin{tabular}{|c|c|c|c|c|c|}
\hline \multirow[b]{2}{*}{ Individual/Demographic } & \multicolumn{5}{|c|}{ Time Physical Activity (min/day) } \\
\hline & $n(\%)$ & $\begin{array}{c}\text { Self-Reported } \\
\text { Leisure-Time Brisk } \\
\text { Walking } \\
\end{array}$ & $p$ Trend & OM-MVPA & $p$ Trend \\
\hline Sex & $218(100)$ & $22.0(28.4)$ & 0.598 & $17.3(23.0)$ & $<0.001$ \\
\hline Men & $106(48.6)$ & $23.0(26.9)$ & & $23.0(28.1)$ & \\
\hline Women & $112(51.4)$ & $21.0(29.8)$ & & $11.8(15.1)$ & \\
\hline Age (years) & $218(100)$ & $22.0(28.4)$ & 0.880 & $17.3(23.0)$ & 0.116 \\
\hline$>65$ & $102(46.8)$ & $22.3(31.0)$ & & $14.7(18.8)$ & \\
\hline$\leq 65$ & $116(53.2)$ & $21.7(25.9)$ & & $19.5(26.1)$ & \\
\hline Educational level & $218(100)$ & $22.0(28.4)$ & 0.223 & $17.3(23.0)$ & 0.149 \\
\hline Primary school or less & $132(60.6)$ & $20.2(29.9)$ & & $15.3(19.1)$ & \\
\hline Secondary school or higher & $86(39.4)$ & $24.8(25.7)$ & & $20.3(27.9)$ & \\
\hline Self-rated health & $216(100)$ & $21.4(26.3)$ & 0.006 & $17.0(22.9)$ & $<0.001$ \\
\hline Excellent/very good/good & $145(67.1)$ & $24.6(27.9)$ & & $20.2(25.8)$ & \\
\hline Fair/poor & $71(32.9)$ & $14.8(21.7)$ & & $10.5(13.1)$ & \\
\hline Precipitation (mm) & $218(100)$ & $22.0(28.4)$ & 0.731 & $17.3(23.0)$ & 0.222 \\
\hline Not rainy period & 119 & $21.4(28.5)$ & & $18.9(26.4)$ & \\
\hline Rainy period & 99 & $22.7(28.3)$ & & 15.2 (18.2) & \\
\hline
\end{tabular}

Values shown are $n(\%)$ and mean (sd) for categorical variables. The $p$-value for trend is computed from the.

The total number of POS within or partially within the sausage network walkable buffer was $10.03( \pm 5.91)$ with a mean area of $0.17( \pm 0.25) \mathrm{km}^{2}$ (Table 2). The furthest distance to a POS was the distance to the nearest beach with a mean of $3.9 \mathrm{~km}$, followed by distance to the coast of just under $3 \mathrm{~km}$; conversely, there was a considerable very low distance to the nearest Park with under $0.3 \mathrm{~km}$. Our population has an average of $4.24( \pm 3.15) \mathrm{km}$ of healthy routes and only $0.04( \pm 0.12) \mathrm{km}$ of coastline contained or intersected within the $1000 \mathrm{~m}$ sausage network walkable buffer. The largest number of POS within or partially within the sausage network walkable buffer were parks with a mean number of $8.5( \pm 5.09)$ and a mean area of $0.16( \pm 0.25) \mathrm{km}^{2}$.

Table 2. Descriptive statistics of public open spaces (POS) for $1000 \mathrm{~m}$ sausage network walkable street buffer. Values shown are mean (SD).

\begin{tabular}{ll}
\hline Objectively-Assessed POS & Mean (SD) \\
\hline Distance to the coast $(\mathrm{km})$ & $\mathbf{2 . 9 8 ( 1 . 7 1 )}$ \\
Distance to the healthy route for walking $(\mathrm{km})$ & $\mathbf{0 . 4 5}(\mathbf{0 . 5 8 )}$ \\
Distance to the nearest sports facility $(\mathrm{km})$ & $\mathbf{0 . 8 5}(\mathbf{0 . 6 6 )}$ \\
Distance to the nearest beach $(\mathrm{km})$ & $\mathbf{3 . 8 9}(\mathbf{1 . 5 5 )}$ \\
Distance to the nearest park $(\mathrm{km})$ & $\mathbf{0 . 2 8}(\mathbf{0 . 4 )}$ \\
Coastline contained or intersected by buffer $(\mathrm{Km})$ & $\mathbf{0 . 0 4}(\mathbf{0 . 1 2})$ \\
Healthy routes contained or intersected by buffer $(\mathrm{Km})$ & $\mathbf{4 . 2 4}(\mathbf{3 . 1 5})$ \\
No. sports facilities contained or intersected by buffer & $\mathbf{1 . 4 9 ( 1 . 3 4 )}$ \\
Area of sports facilities contained or intersected by buffer $\left(\mathrm{Km}^{2}\right)$ & $\mathbf{0 . 0 2}(\mathbf{0 . 0 3})$ \\
No. parks contained or intersected by buffer & $\mathbf{8 . 5 ( 5 . 0 9 )}$ \\
Areas of parks contained or intersected by buffer $\left(\mathrm{Km}^{2}\right)$ & $\mathbf{0 . 1 6}(\mathbf{0 . 2 5 )}$ \\
No. beaches contained or intersected by buffer & $\mathbf{0 . 0 4}(\mathbf{0 . 1 9 )}$ \\
Areas of beaches contained or intersected by buffer $\left(\mathrm{Km}^{2}\right)$ & $\mathbf{0}(0)$ \\
No. POS contained or intersected by buffer & $\mathbf{1 0 . 0 3 ( 5 . 9 1 )}$ \\
Areas of POS contained or intersected by buffer $\left(\mathrm{Km}^{2}\right)$ & $\mathbf{0 . 1 7}(\mathbf{0 . 2 5})$ \\
\hline
\end{tabular}

Abbreviations: SD, Standard deviation; POS, public open spaces; Km, Kilometer; $\mathrm{Km}^{2}$, Square kilometer. 
Precipitation over the study is reflected in Figure 4. Daily precipitation ranged from 0 to 17.4 $\mathrm{mm}$ with $53 \%$ of days being completely dry with no precipitation during the accelerometer wearing period. The overall mean daytime temperature in the study area was $19.9^{\circ} \mathrm{C}$.

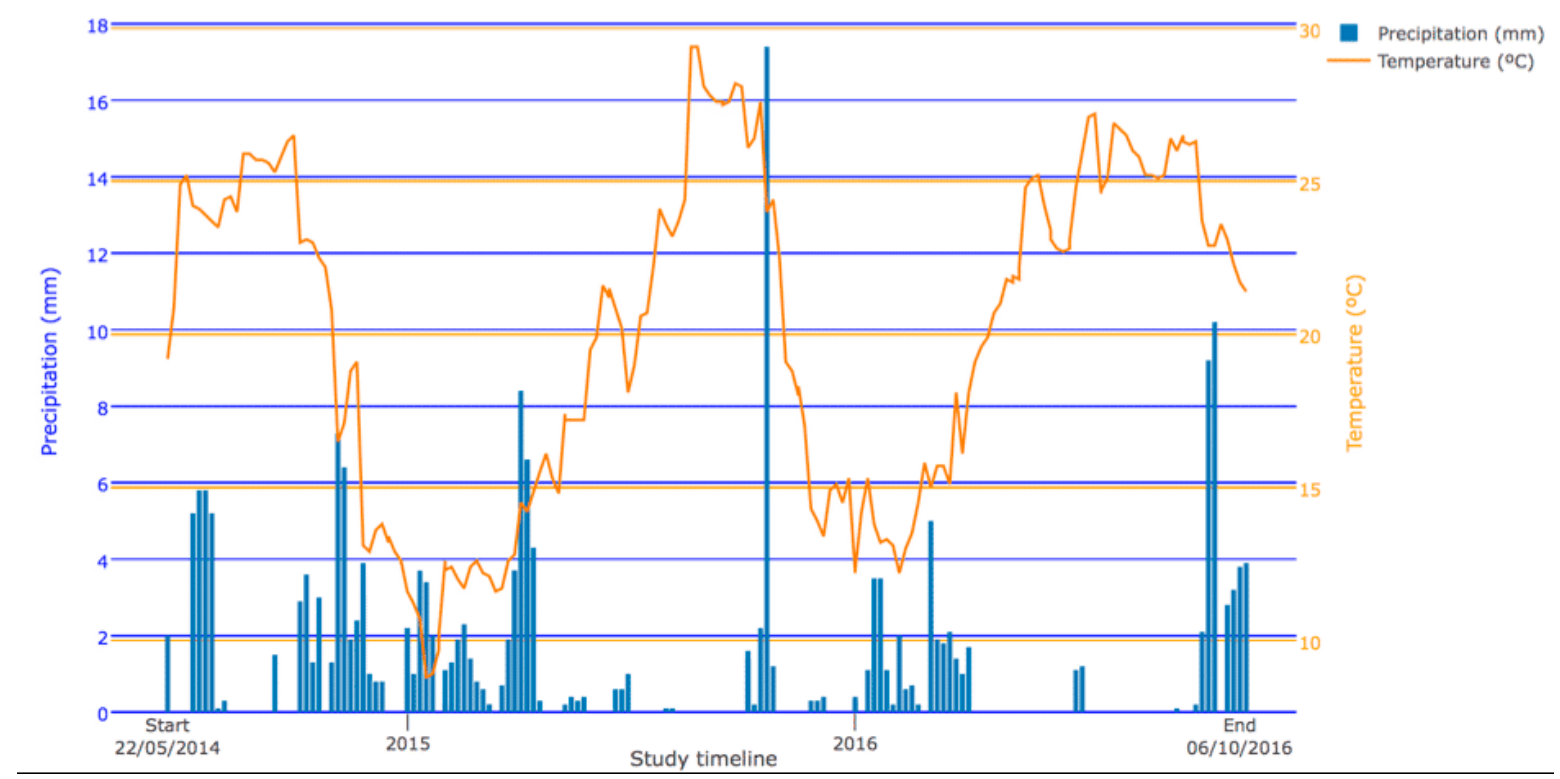

Figure 4. Mean daily precipitation $(\mathrm{mm})$ and mean temperature $\left({ }^{\circ} \mathrm{C}\right)$ during the study from closest participants' resident weather station.

\subsection{Associations of POS with Self-Reported Leisure-Time Brisk Walking}

Table 3 shows the association between distance to POS, sums of areas and counts within each sausage network walkable buffer of $1 \mathrm{~km}$ and self-reported leisure-time brisk walking and OM-MVPA. Both self-reported leisure-time brisk walking and OM-MVPA were adjusted by individual-level covariates.

Overall no statistically significant associations were observed between POS and self-reported leisure-time brisk walking. A positive, significant association was only observed between the distance of healthy routes contained or intersected by buffer and OM-MVPA (GAM, $p=0.022$ ). Increments of $1 \mathrm{~km}$ of healthy routes contained or intersected by a $1 \mathrm{~km}$ sausage network walkable buffer were associated with an increase of $1.09 \cdot \mathrm{min} /$ day of OM-MVPA.

A positive, borderline significant association was observed on the distance to the coast and number of beaches contained or intersected by the buffer in the self-reported leisure-time brisk (GAM, $p=0.05$ ), but was not significantly associated with OM-MVPA. A negative, borderline significant association was observed between the distance of coastline and areas of parks and self-reported brisk walking and a borderline significant association between coastline and OM-MVPA. The number of parks and the number of total POS contained or intersected by buffer were also found positive borderline significant associated with OM-MVPA.

We tested the interaction between each POS and rain during the accelerometer wearing period on OM-MVPA. The only significant interaction was observed between the distance of healthy routes contained or intersected by buffer and OM-MVPA (interaction: $p=0.042$ ). Then we analyzed the association between the distance of healthy routes contained or intersected by the sausage buffer and OM-MVPA on rainy periods and non-rainy periods separately (stratified analyses). For non-rainy periods we found a positive significant association ( $(=2.022 ; p=0.006)$ with a $95 \%$ confidence interval of $(0.595 ; 3.448)$. Increments of $1 \mathrm{~km}$ of healthy routes contained or intersected by a $1 \mathrm{~km}$ sausage network walkable buffer, were associated with an increase of $2.02 \cdot \mathrm{min} /$ day of OM-MVPA. However, during rainy periods, no significant association was found $(\Omega=-0.066 ; 95 \% \mathrm{CI}$ $=-1.171 ; 1.04 ; p=0.908$ ) between healthy routes and OM-MVPA. 
Table 3. Summary of the results associations between access to POS and self-reported leisure-time brisk walking measure and 10 minutes bouts OM-MVPA. The results for the following model comparisons are provided: Covariate-adjusted POS GAMs.

\begin{tabular}{|c|c|c|c|c|c|c|}
\hline \multirow[t]{2}{*}{ Predictor Variable } & \multicolumn{3}{|c|}{$\begin{array}{c}\text { Self-Reported Leisure-Time } \\
\text { Brisk Walking }\end{array}$} & \multicolumn{3}{|c|}{ OM-MVPA } \\
\hline & B & $95 \% \mathrm{CI}$ & $p$ & B & $95 \% \mathrm{CI}$ & $p$ \\
\hline Distance to the coast $(\mathrm{km})$ & 2.053 & $0.004 ; 4.102$ & 0.051 & 0.269 & $-1.478 ; 2.015$ & 0.763 \\
\hline $\begin{array}{l}\text { Distance to the healthy } \\
\text { route for walking }(\mathrm{km})\end{array}$ & 2.277 & $-3.794 ; 8.347$ & 0.463 & -1.311 & $-6.443 ; 3.821$ & 0.617 \\
\hline $\begin{array}{l}\text { Distance to the nearest } \\
\text { sports facility }(\mathrm{km})\end{array}$ & -2.544 & $-7.827 ; 2.738$ & 0.346 & -1.469 & $-5.937 ; 2.999$ & 0.520 \\
\hline $\begin{array}{l}\text { Distance to the nearest } \\
\text { beach }(\mathrm{km})\end{array}$ & 0.519 & $-1.736 ; 2.773$ & 0.652 & -1.393 & $-3.289 ; 0.504$ & 0.151 \\
\hline $\begin{array}{l}\text { Distance to the nearest } \\
\text { park }(\mathrm{km})\end{array}$ & 3.128 & $-5.647 ; 11.903$ & 0.486 & -2.722 & $-10.135 ; 4.691$ & 0.473 \\
\hline $\begin{array}{l}\text { Coastline contained or } \\
\text { intersected by buffer } \\
(\mathrm{Km})\end{array}$ & -26.579 & $-56.196 ; 3.038$ & 0.080 & -22.97 & $-47.98 ; 2.046$ & 0.073 \\
\hline $\begin{array}{l}\text { Healthy routes contained } \\
\text { or intersected by buffer } \\
(\mathrm{Km})\end{array}$ & -0.131 & $-1.241 ; 0.98$ & 0.818 & 1.093 & $0.166 ; 2.019$ & 0.022 \\
\hline $\begin{array}{l}\text { No. sports facilities } \\
\text { contained or intersected } \\
\text { by buffer }\end{array}$ & 0.340 & $-2.259 ; 2.939$ & 0.798 & 1.068 & $-1.123 ; 3.26$ & 0.340 \\
\hline $\begin{array}{l}\text { Area of sports facilities } \\
\text { contained or intersected } \\
\text { by buffer }\left(\mathrm{Km}^{2}\right)\end{array}$ & 57.383 & $-52.54 ; 167.31$ & 0.307 & -7.693 & $-100.785 ; 85.399$ & 0.871 \\
\hline $\begin{array}{l}\text { No. parks contained or } \\
\text { intersected by buffer }\end{array}$ & -0.218 & $-0.903 ; 0.468$ & 0.534 & 0.516 & $-0.06 ; 1.092$ & 0.080 \\
\hline $\begin{array}{l}\text { Areas of parks contained } \\
\text { or intersected by buffer } \\
\left(\mathrm{Km}^{2}\right)\end{array}$ & -12.701 & $-26.636 ; 1.235$ & 0.075 & -6.245 & $-18.077 ; 5.586$ & 0.302 \\
\hline $\begin{array}{l}\text { No. beaches contained or } \\
\text { intersected by buffer }\end{array}$ & 17.610 & $-0.872 ; 36.093$ & 0.063 & -7.074 & $-22.788 ; 8.641$ & 0.379 \\
\hline $\begin{array}{l}\text { Areas of beaches } \\
\text { contained or intersected } \\
\text { by buffer }\left(\mathrm{Km}^{2}\right)\end{array}$ & 632.003 & $-490.6 ; 1754.6$ & 0.271 & -402.8 & $-1352.315 ; 546.8$ & 0.407 \\
\hline $\begin{array}{l}\text { No. POS contained or } \\
\text { intersected by buffer }\end{array}$ & -0.126 & $-0.716 ; 0.464$ & 0.676 & 0.430 & $-0.066 ; 0.925$ & 0.091 \\
\hline $\begin{array}{l}\text { Areas of POS contained } \\
\text { or intersected by buffer } \\
\left(\mathrm{Km}^{2}\right)\end{array}$ & -11.598 & $-25.507 ; 2.31$ & 0.104 & -6.393 & $-18.187 ; 5.4$ & 0.289 \\
\hline
\end{tabular}

Abbreviations: $\$$, non-standardized coefficient; $95 \% \mathrm{CI}$, confidence interval; $p, p$-value. $B$ indicates change in self-reported leisure-time brisk walking per minutes per day (min/day) per increment (in 1 $\mathrm{Km}, 1 \mathrm{Km}^{2}$ or count) in access to public open spaces (POS). Individual-level covariate (gender, education level and self-rated health). 


\section{Discussion}

\subsection{Main Findings}

This study investigated the association between access to POS on self-reported and objectively-measured PA, and the interaction of weather conditions on this association in older adults participating in the PREDIMED-Plus-Baleares. Overall findings showed that increments in kilometers of healthy routes contained or intersected by a $1 \mathrm{~km}$ sausage network walkable buffer, were associated with an increase on 10 minutes bouts OM-MVPA. This association was only evident on non-rainy days.

\subsection{Built Environment, Weather and Physical Activity}

The findings of this study show that the urban built environment, such as POS, are not associated with physical activity in older adults. Our results correspond to our previous results with another population shown non-significant relationships between POS accessibility and self-reported leisure time physical activity [27]. In addition, a recent systematic review and meta-analysis in other settings those show a non-significant relationships between POS accessibility and self-reported or objectively-measured leisure-time walking [3]. We found that a novel urban built environment POS, as kilometers of healthy routes promoted by the local government, contained or intersected by a 1 $\mathrm{km}$ sausage network walkable buffer was associated with objectively-measured physical activity. Furthermore, this increment doubled when only non-rainy periods were included. Although we were unable to differentiate if these healthy routes correlated with others common urban built environment measures commonly used in physical activity and health research, such as residential density, public transport stop access, road intersection density, land use mix or walkability index, we suspect these conditions might strongly affect the local government health policies in the construction of these healthy routes. Moreover, these urban built environment measures show significant relationships between POS accessibility and leisure-time walking [3].

Despite the fact that we observed that only healthy routes had an interaction between rain during the accelerometer wearing period on OM-MVPA, it seems plausible to consider that rainy conditions may reduce outdoor activity in older adults. Our results are in contrast to qualitative research findings indicating that concerns over safety, fear of falling, and injury are potential barriers to outdoor activity in older adults[28]. Our findings may be explained by the characteristics of the Mediterranean climate in our study area with fewer raining periods compared to some other regions.

\subsection{Strengths and Limitations}

Strengths of the study include the fact that it was based on a baseline of an ongoing 6-year multi-center, randomized, parallel-group of older Mediterranean adults with self-reported and objective measures of physical activity for seven days. We evaluated the interaction of weather conditions on the association of objectively measured POS variables with objective accelerometer-measured physical activity, that has been subjected to a limited number of studies on this topic, despite its singularities. In addition, we applied self-reported leisure-time brisk walking and $10 \mathrm{~min}$ bouts objectively-measured moderate-to-vigorous physical activity contrary to context-free measures of physical activity, such as the total amount of physical activity. For our population both physical activity measures (self-reported leisure-time brisk walking and OM-MVPA) have been significantly strongly correlated with each other. We evaluated a wide range of POS, including access to the beach, coast, and healthy routes for walking, variables that are relevant to our population and may influence leisure-time walking [14]. For the evaluation of access to POS, we used a sausage network walkable street buffer, instead of walkable street buffers or radial buffer to minimize measurement errors [11].

A limitation of this study is its cross-sectional design; therefore, we cannot infer causality or establish that the exposures preceded the outcomes. Hence, we cannot use these results to evaluate 
their policy implications. Nevertheless, cross-sectional studies are important for expediently identifying factors that might be targeted to improve physical activity in future longitudinal studies.

Another limitation in this study is that the study population was enrolled from primary care facilities of medium size city Palma de Mallorca, from an island situated in the Mediterranean Region in Spain. The population under study is a homogeneous sample of aged participants with obesity and metabolic syndrome, with overall low physical activity levels. Furthermore, the Mediterranean climate is mild with fewer rainy periods compared to some regions in Spain or other countries.

\section{Conclusions}

When promoting physical activity practice, it is important to consider the plausible environmental determinants that may affect this practice. In this elderly population living in a Mediterranean city, only the kilometers of healthy routes contained or intersected by a $1 \mathrm{~km}$ sausage network walkable buffer influenced the accelerometer measured MVPA 10 min bouts and rainy conditions during the accelerometer wear period appeared to be an important factor related to active ageing. Future work should focus on larger sample size, integrating a longitudinal design, and greater heterogeneity in the built environment access. PREDIMED-Plus as a multi-center randomized trial presents an excellent opportunity for futures urban environmental studies.

Author Contributions: A.C. Conceived the study, performed geocoding and data preparation for statistical analysis, performed statistical analysis and drafted the manuscript. M.R. Assisted with geocoding and data preparation and supervised. J.M. Contributed to the statistical analysis and statistical analysis discussion section of the study. J.W. Performed processed accelerometer data, preparation of objective measures of physical activity data for statistical analysis and supervised. M.C. contributed to the statistical analysis discussion section of the study and as a native English speaker reviewed all manuscript drafts. J.B. Performed processed accelerometer data, preparation of objective measures of physical activity data for statistical analysis and supervised statistical analysis. N.P. performed processed accelerometer data, preparation of objective measures of physical activity data for statistical analysis. M.M. participated in the recruitment of participants and conduction of the trial. E.C. performed geocoding of healthy routes for walking and contributed to the discussion section of the study. M.F. is the principal investigator of the CIBER Fisiopatología de la Obesidad y Nutrición (CIBEROBN) and reviewed all manuscript drafts. D.R. is the principal investigator of the PREDIMED-Plus study in the Balearic Islands and supervised A.C. in study design and manuscript preparation and reviewed all manuscript drafts. All authors read and approved the final manuscript.

Funding: Instituto de Investigación en Salud Carlos III (PI14/00853 and PI17/00525). Cofunded by FEDER.

Acknowledgments: The authors wish to thank the participants in the city of Palma de Mallorca, Spain who participated in the PredimedPlus study for their collaboration, and the PredimedPlus personnel and investigators who collected, catalogued, and provided the data that has made this study possible, as well as all affiliated primary care centers, for their excellent work. We appreciate the transparency of the geographic data necessary for this study to the Municipal Sports Institute of the City of Palma and the Department of Infrastructure and Accessibility of the City Council of Palma. M.C. is the recipient of a pre-doctoral FPI scholarship from the Conselleria d'Innovació, Recerca i Turisme of the regional Government of the Balearic Islands co-financed by the European Social Fund as part of the FSE 2014-2020 operational program.

Conflicts of Interest: The authors declare no conflict of interest.

\section{References}

1. Guthold, R.; Stevens, G.A.; Riley, L.M.; Bull, F.C. Worldwide trends in insufficient physical activity from 2001 to 2016: A pooled analysis of 358 population-based surveys with 1.9 million participants. Lancet Glob. Health 2018, 6, e1077-e1086.

2. Lee, I.-M.; Shiroma, E.J.; Lobelo, F.; Puska, P.; Blair, S.N.; Katzmarzyk, P.T.; Lancet Physical Activity Series Working Group Effect of physical inactivity on major non-communicable diseases worldwide: An analysis of burden of disease and life expectancy. Lancet 2012, 380, 219-229. 
3. Van Cauwenberg, J.; Nathan, A.; Barnett, A.; Barnett, D.W.; Cerin, E.; the Council on Environment and Physical Activity (CEPA)-Older Adults Working Group. Relationships between Neighbourhood Physical Environmental Attributes and Older Adults' Leisure-Time Physical Activity: A Systematic Review and Meta-Analysis. Sports Med. 2018, 380, 1-26.

4. Barnett, D.W.; Barnett, A.; Nathan, A.; Van Cauwenberg, J.; Cerin, E.; Council on Environment and Physical Activity (CEPA)-Older Adults working group Built environmental correlates of older adults' total physical activity and walking: A systematic review and meta-analysis. Int. J. Behav. Nutr. Phys. Act. 2017, 14, 103.

5. Wu, Y.-T.; Luben, R.; Wareham, N.; Griffin, S.; Jones, A.P. Weather, day length and physical activity in older adults: Cross-sectional results from the European Prospective Investigation into Cancer and Nutrition (EPIC) Norfolk Cohort. PLoS ONE 2017, 12, e0177767.

6. Klenk, J.; Büchele, G.; Rapp, K.; Franke, S.; Peter, R.; ActiFE Study Group Walking on sunshine: Effect of weather conditions on physical activity in older people. J. Epidemiol. Community Health 2012, 66, 474-476.

7. Witham, M.D.; Donnan, P.T.; Vadiveloo, T.; Sniehotta, F.F.; Crombie, I.K.; Feng, Z.; McMurdo, M.E.T. Association of Day Length and Weather Conditions with Physical Activity Levels in Older Community Dwelling People. PLoS ONE 2014, 9, e85331.

8. Loyen, A.; Van Hecke, L.; Verloigne, M.; Hendriksen, I.; Lakerveld, J.; Steene-Johannessen, J.; Vuillemin, A.; Koster, A.; Donnelly, A.; Ekelund, U.; et al. Variation in population levels of physical activity in European adults according to cross-European studies: A systematic literature review within DEDIPAC. Int. J. Behav. Nutr. Phys. Act. 2016, 13, 72.

9. Alberti, K.G.M.M.; Eckel, R.H.; Grundy, S.M.; Zimmet, P.Z.; Cleeman, J.I.; Donato, K.A.; Fruchart, J.-C.; James, W.P.T.; Loria, C.M.; Smith, S.C.; International Diabetes Federation Task Force on Epidemiology and Prevention; Hational Heart, Lung, and Blood Institute; American Heart Association; World Heart Federation; International Atherosclerosis Society; International Association for the Study of Obesity Harmonizing the metabolic syndrome: A joint interim statement of the International Diabetes Federation Task Force on Epidemiology and Prevention; National Heart, Lung, and Blood Institute; American Heart Association; World Heart Federation; International Atherosclerosis Society; and International Association for the Study of Obesity. In American Heart Association, Inc. 2009; Volume 120, pp. 1640-1645.

10. Forsyth, A.; Larson, N.; Lytle, L.; Mishra, N.; Neumark-Sztainer, D.; Noble, P.; Van Riper, D. LEAN-GIS protocols (Local Environment for Activity and Nutrition-Geographic Information Systems). Available at: http://designforhealth.net/wp-content/uploads/2012/12/LEAN_Protocol_V2_1_010112rev.pdf (accessed on 23 April 2018).

11. Frank, L.D.; Fox, E.H.; Ulmer, J.M.; Chapman, J.E.; Kershaw, S.E.; Sallis, J.F.; Conway, T.L.; Cerin, E.; Cain, K.L.; Adams, M.A.; et al. International comparison of observation-specific spatial buffers: Maximizing the ability to estimate physical activity. Int. J. Health Geogr. 2017, 16, 4.

12. Apparicio, P.; Seguin, A.-M. Measuring the Accessibility of Services and Facilities for Residents of Public Housing in Montreal. Urban Stud. 2006, 43, 187-211.

13. White, M.P.; Wheeler, B.W.; Herbert, S.; Alcock, I.; Depledge, M.H. Coastal proximity and physical activity: Is the coast an under-appreciated public health resource? Prev. Med. 2014, 69, 135-140.

14. Winters, M.; Buehler, R.; Götschi, T. Policies to Promote Active Travel: Evidence from Reviews of the Literature. Curr. Environ. Health Rep. 2017, 4, 278-285.

15. Molina, L.; Sarmiento, M.; Peñafiel, J.; Donaire, D.; Garcia-Aymerich, J.; Gomez, M.; Ble, M.; Ruiz, S.; Frances, A.; Schröder, H.; et al. Validation of the Regicor Short Physical Activity Questionnaire for the Adult Population. PLoS ONE 2017, 12, e0168148.

16. Elosua, R.; Marrugat, J.; Molina, L.; Pons, S.; Pujol, E. Validation of the Minnesota Leisure Time Physical Activity Questionnaire in Spanish men. The MARATHOM Investigators. Am. J. Epidemiol. 1994, 139, 1197-1209.

17. Elosua, R.; Garcia, M.; Aguilar, A.; Molina, L.; Covas, M.I.; Marrugat, J. Validation of the Minnesota Leisure Time Physical Activity Questionnaire In Spanish Women. Investigators of the MARATDON Group. Med. Sci. Sports Exerc. 2000, 32, 1431-1437.

18. Hart, T.L.; Swartz, A.M.; Cashin, S.E.; Strath, S.J. How many days of monitoring predict physical activity and sedentary behaviour in older adults? Int. J. Behav. Nutr. Phys. Act. 2011, 8, 62.

19. Freedson, P.S.; Miller, K. Objective monitoring of physical activity using motion sensors and heart rate. Res. Q. Exerc. Sport 2000, 71, S21-S29. 
20. Pérez-Tasigchana, R.F.; León-Muñoz, L.M.; López-García, E.; Banegas, J.R.; Rodríguez-Artalejo, F.; Guallar-Castillón, P. Mediterranean Diet and Health-Related Quality of Life in Two Cohorts of Community-Dwelling Older Adults. PLoS ONE 2016, 11, e0151596.

21. Subirana, I.; Sanz, H.; Vila, J. Building bivariate tables: The compareGroups package for R. J. Stat. Softw. 2014, 57, 1-16.

22. Cerin, E.; Cain, K.L.; Conway, T.L.; Van Dyck, D.; Hinckson, E.; Schipperijn, J.; De Bourdeaudhuij, I.; Owen, N.; Davey, R.C.; Hino, A.A.F.; et al. Neighborhood environments and objectively measured physical activity in 11 countries. Med. Sci. Sports Exerc. 2014, 46, 2253-2264.

23. Wood, S.N. Generalized Additive Models: An Introduction with R, 2nd ed.; Chapman and Hall/CRC, Boca Raton, Florida, USA, 2017.

24. Wood, S.N. Generalized Additive Models: An Introduction with R; Chapman and Hall/CRC, Boca Raton, Florida, USA, 2006.

25. Wood, S.; Scheipl, F. gamm4: Generalized Additive Mixed Models Using mgcv and lme4. R Package Version 0.2-3. 2014.

26. Global Recommendations on Physical Activity for Health; World Health Organization: Geneva, Switzerland, 2010.

27. Colom, A.; Fiol, M.; Ruiz, M.; Compa, M.; Morey, M.; Moñino, M.; Romaguera, D. Association between Access to Public Open Spaces and Physical Activity in a Mediterranean Population at High Cardiovascular Risk. Int. J. Environ. Res. Public Health 2018, 15, 1285.

28. Chippendale, T.; Boltz, M. The Neighborhood Environment: Perceived Fall Risk, Resources, and Strategies for Fall Prevention. Gerontologist 2015, 55, 575-583.

(C) 2018 by the authors. Licensee MDPI, Basel, Switzerland. This article is an open access article distributed under the terms and conditions of the Creative Commons Attribution (CC BY) license (http://creativecommons.org/licenses/by/4.0/). 